\title{
AN ELECTROSTATICALLY-ACTUATED MICROVALVE FOR SEMICONDUCTOR GAS FLOW CONTROL
}

\author{
Janet K. Robertson and Kensall D. Wise \\ Center for Integrated Sensors and Circuits \\ Department of Electrical Engineering and Computer Science \\ The University of Michigan \\ Ann Arbor, MI 48109-2122
}

\begin{abstract}
Semiconductor manufacturing presents important challenges in terms of the sensors needed for closed-loop process control. In particular, improved trimmer valves are needed to precisely control gas flows below $10 \mathrm{sccm}$. This paper reports a small electrostatically-actuated microvalve which has been integrated with micromachined flow channels to form an integrated microflow controller. The current valves actuate at $80 \mathrm{~V}$, but actuation voltages as low as $40 \mathrm{~V}$ have been obtained. A gas flow model of the microvalve in the molecular, viscous, and transition flow regimes has been developed. The model has been verified by data obtained from microvalves. The maximum calculated flow rate for eight identical microvalves and flow channels in parallel is $0.69 \mathrm{sccm}$ with a minimum predicted leak rate of $3.8 \times 10^{-3} \mathrm{sccm}$. The response time of the valve is $\sim 100 \mu \mathrm{sec}$. Assuming a minimum operating pulse width of $10 \mathrm{msec}$, the valve is capable of delivering a $14.5 \times 10^{-6}$ standard $\mathrm{cm}^{3}$ pulse of gas at 100Torr applied differential pressure.
\end{abstract}

\section{INTRODUCTION}

Many semiconductor processes such as MOCVD, LPCVD and RIE require precise control of gas flow rates at very low operating pressures. This paper reports an electrostaticallyactuated trimmer microvalve capable of high precision gas flow control. Electrostatically-actuated valves offer several advantages over other valve types. They are low power and very small, permitting multi-valve assemblies with small chip sizes and very small dead volumes. The microvalve reported here extends a previously reported device [1] via several structural and process changes. This valve differs significantly from other recently reported valves which have been aimed at higher flow rates and higher operating pressures. $[2,3]$

Figure 1 shows a perspective drawing of the integrated microflow controller. Gas enters the device through a bulk micromachined gas inlet hole in the silicon cap. A free standing double-end-clamped beam is positioned beneath the gas inlet. The beam acts as a microvalve because it can be electrostatically deflected either upward to seal against the gas inlet, or downward out of the gas flow path. The gas, after entering the device through the inlet, flows parallel to the glass substrate through flow channels micromachined in the silicon cap. The gas exits the device through a $500 \mu \mathrm{m}$ diameter outlet orifice drilled in the glass substrate. A differential pressure sensor can also be fully integrated with the device. Since the pressure sensor was developed previously [4] and is known to function well, it was not integrated with the microvalves reported here, thereby simplifying the fabrication process.

The microflow controller contains eight silicon beamsforming eight microvalves, each with its own flow channel- leading to an outlet hole drilled in the center of the die. The beams are $600 \mu \mathrm{m}$ long, $240 \mu \mathrm{m}$ wide, $3 \mu \mathrm{m}$ thick and are $3 \mu \mathrm{m}$ above the glass substrate. The beams are positioned beneath the inlet orifice in an inlet cavity approximately $7.8 \mu \mathrm{m}$ deep. The flow channels are $400 \mu \mathrm{m}$ wide and $1200 \mu \mathrm{m}$ long. The flow channel height can be varied, but for the device reported here, it was $\sim 12.8 \mu \mathrm{m}$.

The valve is actively pulled into both the on- and the offstates using the cap, beam, and substrate metallization as three independent electrodes. The valve reported here actuates at $80 \mathrm{~V}$, but actuation voltages as low as $40 \mathrm{~V}$ have been observed. The individual valves have a theoretical operating range of $4.8 \times 10^{-4} \mathrm{sccm}$ (closed) to $8.7 \times 10^{-2} \mathrm{sccm}$ (opened), with a calculated response time of $100 \mu \mathrm{sec}$.

\section{FABRICATION}

A double-end-clamped single-crystal silicon beam is formed using a five-mask dissolved-wafer process with a waferlevel electrostatic bond to glass. Figure 2 is a photograph of a micromachined beam. The new fabrication sequence uses a robust $\mathrm{Ti} / \mathrm{Pt}$ to $\mathrm{Ti} / \mathrm{Pt}$ lead transfer between the beam and the glass. The metal to metal contact has a series resistance of less than 10 ohms for a $100 \mu \mathrm{m} \times 50 \mu \mathrm{m}$ contact.

The cap wafer was formed by first recessing the front side of the wafer, to form the flow channels, and then bulk micromachining the back side of the wafer, to form the gas inlets. The cap wafer was then sawed and affixed to the glass over the previously formed beams. Since the beam and the cap were completely fabricated before final assembly, the flow channels and the microvalve inlet area could be thoroughly cleaned before the beams were encapsulated.

Figure 3 is a SEM of the $120 \mu \mathrm{m}$ diameter gas inlet. The matrix of metal circles visible around the inlet are standoffs which were used to prevent stiction. The octagonal metal oring around the edge of the inlet is also visible. Figure 4 is a photograph of two completed die. The eight bulk micromachined gas inlets are clearly visible.

\section{THE GAS FLOW CONDUCTANCE}

The gas flow path of the integrated microflow controller can be divided into six parts: the inlet orifice, the beam, the inlet region, the flow channel, the exit region, and the exit port. These regions are shown schematically in Figure 5. The effects of the large inlet orifice and exit port are negligible. In the following sections, the theoretical equations for both the molecular conductance and the viscous conductance for each part of the flow system are reviewed. These equations will then be used to model the conductance of the integrated microflow controller gas flow channels and the microvalve. 


\section{The Molecular Conductance}

The molecular molar flow rate, $Q_{m}$, in sccm, is given by

$$
Q_{m}(S C C M)=k_{m} \cdot \Delta P, \quad k_{m}=\frac{\bar{v} A}{4} W\left[\frac{T_{s}}{P_{s} T}\right]
$$

where $k_{m}$ is the molecular conductance, $W$ is the transmission coefficient, $\bar{v}$ is the mean molecular speed, and $T=296 \mathrm{~K}$ is the measurement temperature. The last term on the right has been included to convert to standard temperature and pressure, $273 \mathrm{~K}$ and $\mathrm{l} \mathrm{atm}$, respectively.

The transmission coefficient is a function of the geometry of the flow channel. For rectangular flow channels, $W$ is given by [5]

$$
W_{R}=\sqrt{\pi \delta} \frac{R}{L}\left\{0.5+\ln \left[\frac{2}{\delta}\right]\right\}
$$

where $L$ is the length of the flow channel, $R$ is the effective radius defined as $\pi R^{2} \equiv a b, a$ and $b$ are the side lengths $(a \leq b)$ and $\delta=a / b$. Equation 2 is valid for long channels $(L / R>100)$, and will be used to calculate $k_{m}$ for the flow channels and the exit region.

The molecular conductance in the inlet region and the conductance between the beam and the cap were modeled as gas flow between two parallel flat plates. The transmission coefficient for two flat plates is given by $W_{m}=w_{I}-w_{2}$ [6] for

$$
\begin{gathered}
w_{1}=0.5\left[1+\sqrt{1+x^{2}}-x\right] \\
w_{2}=\frac{0.66\left\{x-\ln \left[x+\sqrt{x^{2}+1}\right]\right\}^{2}}{x^{3}+3 x^{2}-4-\left(x^{2}+4\right) \sqrt{\left(1+x^{2}\right)}}
\end{gathered}
$$

where $x=L / h$, and $h$ is the plate separation.

If two flow channels with cross-sectional areas $A_{1}$ and $A_{2}$, and transmission coefficients $W_{1}$ and $W_{2}$, are connected in series, the molecular transmission coefficient for the resulting flow channel is given by [7]

$$
\frac{1}{W_{\text {cotal }}}=\frac{1}{W_{1}}+\frac{1}{g W_{2}}-\frac{1}{g}, \quad g=\frac{A_{2}}{A_{1}}
$$

where $W_{\text {total }}$ is the system transmission coefficient based on an effective cross-sectional area of $A_{l}$.

\section{The Viscous Conductance}

For compressible viscous flow, the viscous molar flow rate, $Q_{\nu}$, is given by [8]

$$
Q_{v}(S C C M)=k_{v} \cdot \Delta P, \quad k_{v}=\frac{A D_{h}^{2}}{L \eta \phi} \cdot \frac{2 \bar{P} T_{s}}{P_{s} T}
$$

where $k_{v}$ is the viscous conductance, $D_{h}$ is the hydraulic diameter, $\eta$ is the viscosity, $\Delta P=P_{1}-P_{2}$ is the applied differential pressure, $\bar{P}$ is the average pressure in the flow channel, and $\phi$ is an empirical constant related to the geometry of the flow channel. When two or more flow channels are connected in series, the viscous conductance of the entire system is given by

$$
\frac{1}{k_{v}(\text { total })}=\frac{1}{k_{\nu 1}}+\frac{1}{k_{v 2}}+\frac{1}{k_{v 3}} \ldots
$$

\section{The Transition Conductance}

In the transition region, the conductance can be approximated by [9]

$$
k_{t}=k_{v}+k_{m}\left[\frac{1+2.507 K_{n}^{-1}}{1+3.095 K_{n}^{-1}}\right]
$$

where $K_{n}$ is the Knudsen number.

\section{THE MICROVALVE MODEL}

Before the microvalve could be accurately modeled, the conductances of the inlet region, the flow channel, and the exit region had to be determined. To understand the contribution of each of these regions, two gas flow tests were run.

The first test measured the combined conductance of the flow channel and the exit. The inlet of two valves on a cap die was removed with a diamond saw. This modified cap die was then electrostatically bonded to a glass die. Although the glass die was metallized and an exit port had been drilled in the die, no beams were present. The gas flow rate as a function of applied pressure was then measured. The conductance was then modeled using Equations 1,2, 6, and 8.

The second test measured the combined flow conductance of the inlet, the flow channel and the exit. A complete cap die was electrostatically bonded to a metallized glass die. An exit port had been drilled in the glass die, but as with the previous test, the double-end-clamped beams were omitted. The gas flow rate as a function of applied pressure was then measured. The conductance of the inlet region was modeled as flow through two parallel plates. The total conductance was then modeled by combining the previously developed model for the flow channel and the exit region with the inlet region conductance using Equations 5 and 7. The total transition region conductance was then calculated using Equation 8. Figure 6 is a graph of both the measured and the predicted flow conductance for each of the previous tests.

The gas flow rate through a functioning microvalve and its adjoining flow channel was then measured. The effect of the beam deflection on the system conductance was modeled as flow through two parallel plates. The total system conductance was calculated by combining the model developed in the previous tests with the conductance of the deflecting beam. The microvalve model was partially verified by using the microvalve gas flow data and the microvalve model to estimate the plate separation between the encapsulated beam and the inlet as the valve was actuated. The estimated plate separations are shown in Figure 7 for both an actuated microvalve and an undeflected microvalve. 
The average estimated plate separation in the undeflected state was $1.95 \mu \mathrm{m}$, which was consistent with the valve measured dimensions for an undeflected beam. The measured spacing between the cap and the glass was $\sim 7.85 \mu \mathrm{m}$. The beam was $\sim 3 \mu \mathrm{m}$ from the glass and $\sim 3 \mu \mathrm{m}$ thick. Therefore the beam to inlet spacing for an undeflected beam should have been $\sim 1.85 \mu \mathrm{m}$, which agrees with the estimated spacing of $\sim 1.95 \mu \mathrm{m}$.

\section{DISCUSSION}

When actuated at $80 \mathrm{~V}$ to close the valve, the modeled flow indicated that the beams often closed only to within $0.7-$ $1.0 \mu \mathrm{m}$. Particles from the gas flow test system are suspected to have played a role in this, even though a $0.5 \mu \mathrm{m}$ filter was used to filter the incoming $\mathrm{N}_{2}$ gas line. This is a well known problem with electrostatic actuation which could be overcome using an alternative thermo-pneumatic valve [10]. Such valves could be retrofit into the same basic flow controller structure and would offer more robust actuation, though at the cost of significantly slower speed, higher power, and greater area.

Figure 8 is a graph of the modeled gas flow rate through a single microvalve and its adjoining flow channel. Figure 8 also graphs the modeled total pressure drop across the valve as a function of the beam to inlet spacing. The pressure drop reported in Figure 8 is the pressure drop across the beam and does not include the head loss due to the inlet region. This graph can be used to estimate the degree of flow modulation possible for various beam to inlet separations. If the beam, when fully opened, is approximately $5 \mu \mathrm{m}$ from the inlet, and closes to within $0.1 \mu \mathrm{m}$, the flow rate can be modulated by a factor of $182: 1$ at 100 Torr. For these conditions, the total calculated flow rate for a single microvalve and its adjoining flow channel is $8.7 \times 10^{-2} \mathrm{sccm}$ in the open state and $4.8 \times 10^{-4} \mathrm{sccm}$ in the closed state.

The most attractive feature of these microvalves is their ability to deliver precise gas flows at sub-sccm gas flow rates. For example, with a minimum operating pulse width of $10 \mathrm{msec}$ and a maximum system-limited modulation period of 1 second, this microvalve offers better than 7 bits of precision.

\section{ACKNOWLEDGMENTS}

This work was funded by the Semiconductor Research Corporation under Contract 95-YC-085.

\section{REFERENCES}

1. Robertson, J.K. and K.D. Wise, "A Nested Electrostatically-Actuated Microvalve for an Integrated Microflow Controller", Proc. IEEE Micro Electro Mechanical Systems, January (1994), pp. 7-12.

2. Barth, P.W., C.C. Beatty, L.A. Field, J.W. Baker, and G.B. Gordon, "A Robust Normally-Closed Silicon Microvalve", Solid-State Sensor and Actuator Workshop, June (1994), pp. 248-250.

3. Zdeblick, M.J., "Thermopneumatically-Actuated Microvalves and Integrated Electro-Fluidic Circuits", Solid-State Sensor and Actuator Workshop, June (1994), pp. 251-255.

4. Cho, S.T., K. Najafi, C.L. Lowman, and K.D. Wise, "An Ultrasensitive Silicon Pressure-Based Microflowmeter", IEDM Technical Digest, 499-502 (1989).
5. Steckelmacher, W., "The Effect of Cross-Sectional Shape on the Molecular Flow in Long Tubes", Vacuum, 28, 269-275 (1978).

6. Berman, A.S., "Free Molecular Transmission Probabilities", Journal of Applied Physics, 36, 3356 (1965).

7. Oatley, C.W., "The Flow of Gas through Composite Systems at Very Low Pressures", British Journal of Applied Physics, 8, 15-19 (1956).

8. Olson, R.M., Essentials of Engineering Fluid Mechanics, 4th edition, Harper \& Row, New York (1980).

9. Knudsen, M., Annln. Phys, 28, 75 (1909).

10. Bergstrom, P.L., J. Ji, Y. -N. Liu, M. Kaviany, and K.D. Wise, "Thermally Driven Phase-Change Microactuation", Journal of Micromechanical Systems, March 1995, Vol 4, pp. 10-17.

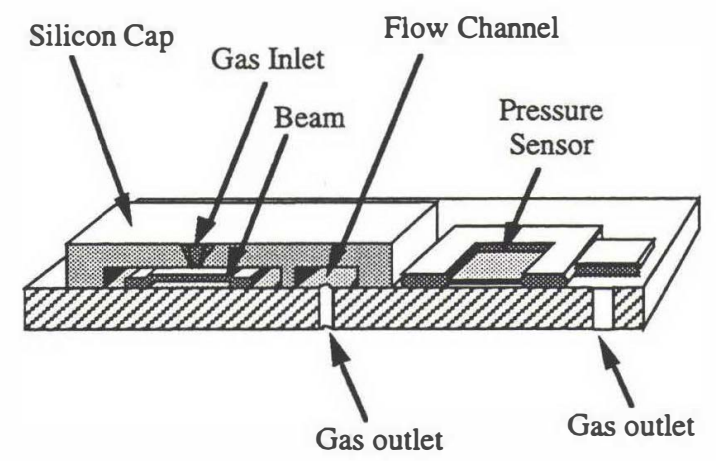

Figure 1. Perspective drawing of the integrated microflow controller. The pressure sensor is formed simultaneously with the beam and is positioned over a separate outlet hole.

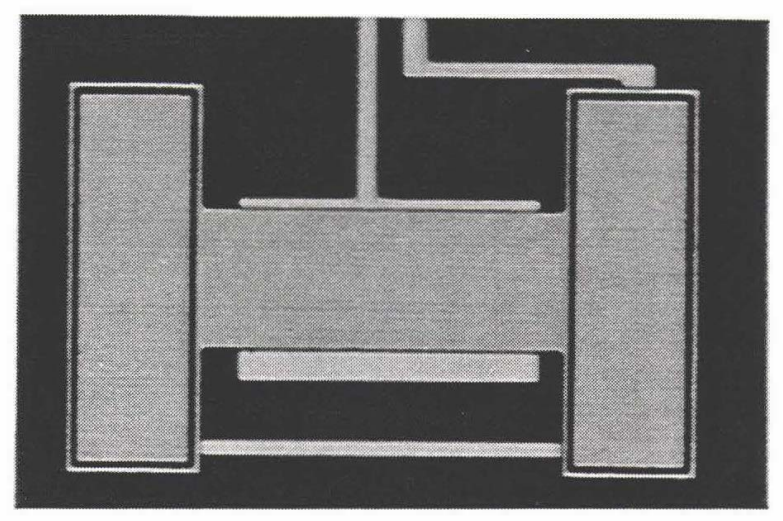

Figure 2. Photograph of a micromachined silicon beam. The beam is $600 \mu \mathrm{m}$ long, $240 \mu \mathrm{m}$ wide and $\sim 3 \mu \mathrm{m}$ thick. The metal pull-down plate is visible beneath the beam. 


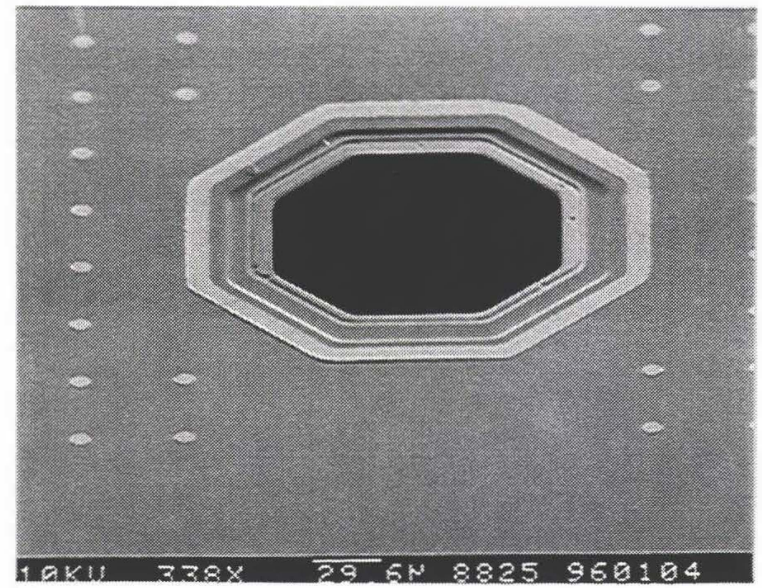

Figure 3. SEM of the microvalve top plate gas inlet.

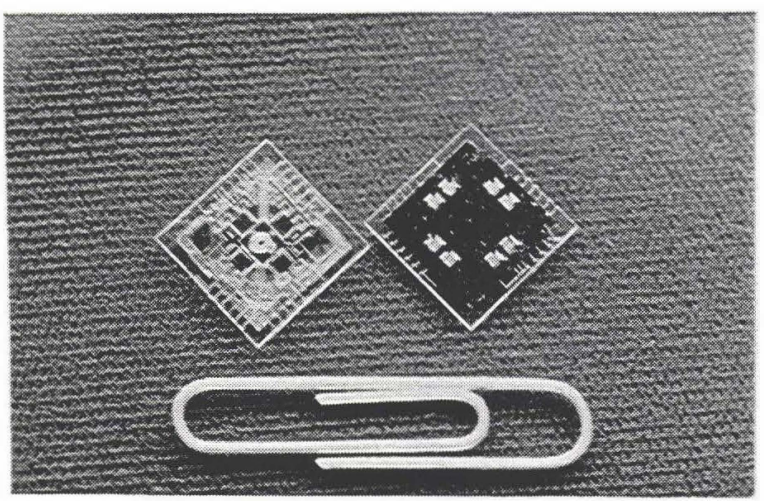

Figure 4. Photograph of two completed microflow controller die. The left die is resting on the silicon cap, and the right die is resting on the glass substrate. The bulk micromachined gas inlets are visible on the right die.

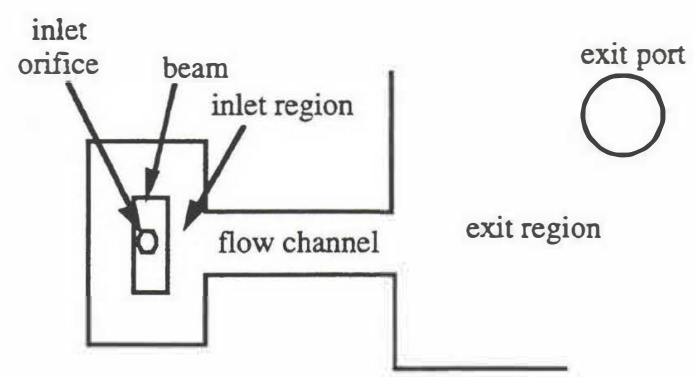

Figure 5. Schematic drawing of a single microvalve and flow channel.

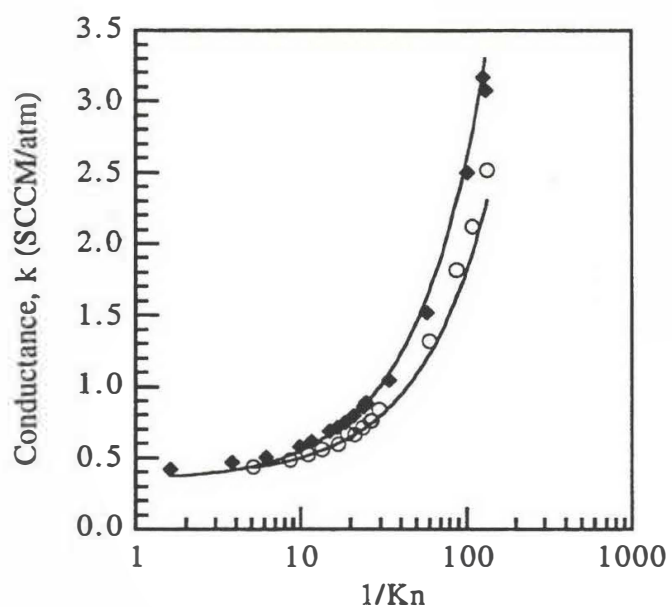

Figure 6. Graph of the measured and modeled conductance for two separate flow tests. Conductance of the flow channel and the exit region. O Conductance of the flow channel, the exit region and the inlet.

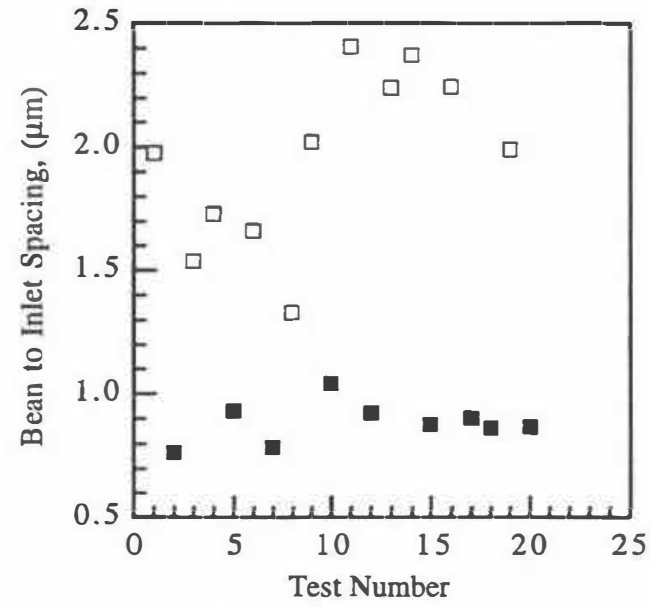

Figure 7. Estimated plate separations inferred from gas flow data taken on undeflected microvalves $\square$, and microvalves actuated between $80 \mathrm{~V}$ and $112 \mathrm{~V} \square$.

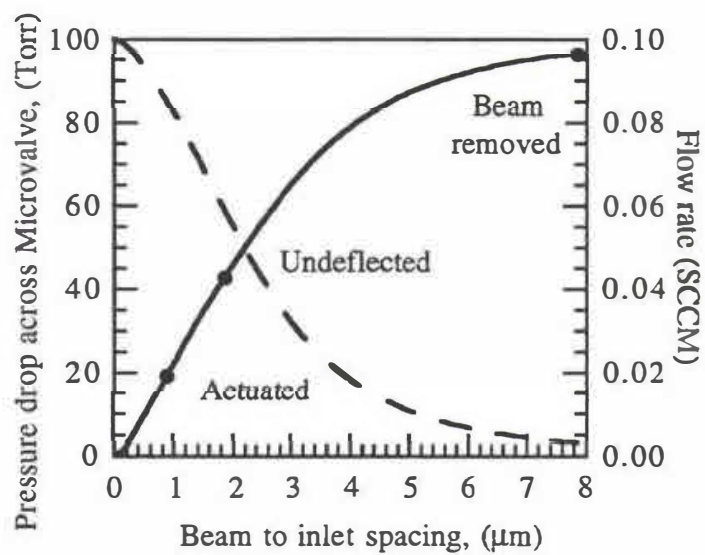

Figure 8. Graph of the modeled microvalve gas flow rate (solid line) and the modeled \% pressure drop (dashed line) across the microvalve as a function of beam to inlet spacing. Total applied pressure was 100 Torr. Measured data points are also shown. 